\title{
AC 2007-2357: GRADUATE/UNDERGRADUATE TEAMING OF ECET STUDENTS FOR APPLIED RESEARCH VIA SENIOR PROJECTS
}

\section{Robert Adams, Western Carolina University}

ROBERT ADAMS is an Assistant Professor of Electrical and Computer Engineering Technology in the Kimmel School of Construction Management, Engineering and Technology at Western Carolina University. His research interests include mathematical modeling of electrocardiographic applications, 3D modeling, and digital signal processing. Dr. Adams is a senior member of IEEE and a member of ASEE.

\section{James Zhang, Western Carolina University}

JAMES Z. ZHANG is an Assistant Professor of Electrical Engineering in the Kimmel School of Construction Management, Engineering and Technology at Western Carolina University. Dr. Zhang's research interests include Communications Theory, Wireless Networks, Bandwidth Efficient Modulation Schemes, Signal Design and Information Coding, and Digital Signal Processing Techniques for Communications. Dr. Zhang is a senior member of IEEE and a member of ASEE.

\section{Kenneth Burbank, Western Carolina University}

KEN BURBANK is an Associate Professor and Director of Electrical Engineering at Western Carolina University. Dr. Burbank is active with IEEE, SME, and TAC of ABET, and strives to bring practical engineering activities into the classroom. His current project is the development of a photonics program within the Electrical Engineering curriculum. 


\title{
Graduate / Undergraduate Teaming of ECET Students for Applied Research via Senior Projects
}

\author{
Robert Adams, James Z. Zhang, Ken Burbank \\ Kimmel School of Construction Management, Engineering and Technology \\ Western Carolina University, Cullowhee, NC 28723
}

\begin{abstract}
In this paper, a method for mentoring undergraduates for future graduate study is presented. We introduce a teaming approach whereby undergraduates are teamed with graduate students in joint projects. The teaming approach prepares undergraduate students for study and research in graduate school. The authors have implemented this approach for the past two years and have noticed positive results including increased graduate enrollment and an increased quality of graduate research. We highlight these results by presenting case studies in which we follow the progression of several students through undergraduate senior projects and graduate studies.
\end{abstract}

\section{Introduction}

In the past few years, the authors reported their efforts of enhancing students' learning by utilizing a systems approach [1] - [4]. These methods focus on the functionality of system blocks to improve students' understanding of system performance parameters. Positive results have been observed in strengthening students knowledge development on certain subjects.

The systems approach has been applied to the development of graduate/undergraduate teaming. In the Fall semester of 2004, we initiated a project in a senior design class in which two undergraduates developed an Ultra Wide Band (UWB) communications system. This effort resulted in a presentation at the National Conference for Undergraduate Research [5]. In the Fall semester of 2005, one of these students continued onto our Master of Science in Technology program. We teamed this student with an undergraduate senior. In the 2005-2006 academic year, this graduate/undergraduate team tested the UWB system under various conditions and provided an analysis of the testing results. The graduate student was able to train the undergraduate to the point where the undergraduate could take leadership of the project. This development of leadership skills was very important for this undergraduate. In the Fall semester of 2006, this second student entered graduate studies, and we teamed this student with a third senior to use the UWB system as a source of broadband energy in the study of 
TABLE I

THREE YEAR SEQUENCE OF GRADUATE/UNDERGRADUATE STUDENT TEAMS.

\begin{tabular}{|c|c|c|c|}
\hline $\begin{array}{l}\text { Academic } \\
\text { Year }\end{array}$ & Teaming Thread & $\underset{2}{\text { Teaming Thread }}$ & $\begin{array}{c}\text { Teaming Thread } \\
\mathbf{3}\end{array}$ \\
\hline $2004-2005$ & $\begin{array}{l}\text { Students 1 \& } 2 \\
\text { (seniors) } \\
\text { on UWB }\end{array}$ & & \\
\hline $2005-2006$ & $\begin{array}{c}\text { Student } 1 \text { (grad) teamed } \\
\text { with Student } 3 \\
\text { (senior) on UWB } \\
\end{array}$ & $\begin{array}{c}\text { Student } 5 \\
\text { (senior) } \\
\text { on facial recognition }\end{array}$ & $\begin{array}{c}\text { Student } 7 \\
\text { (senior) } \\
\text { on acoustic sensors }\end{array}$ \\
\hline $2006-2007$ & $\begin{array}{l}\text { Student } 3 \text { (grad) teamed } \\
\text { with Student } 4 \text { (senior) } \\
\text { on RF testing }\end{array}$ & $\begin{array}{c}\text { Student } 5 \text { (grad) teamed } \\
\text { with Student } 6 \text { (senior) } \\
\text { on Americal Sign Language }\end{array}$ & $\begin{array}{c}\text { Students } 5 \text { and } 7 \text { (grads) teamed } \\
\text { with Student } 8 \text { (senior) } \\
\text { on motion sensors }\end{array}$ \\
\hline
\end{tabular}

Radio Frequency (RF) characteristics of photonic structures. The leadership skills gained by the second student in his senior year allowed him to effectively train the third senior.

\section{Case Studies}

Over the past three years we have developed on-going projects involving undergraduate/graduate teams. The teaming threads that we have developed over this period are shown in Table 1. Eight students, identified in Table 1 as student 1 through student 8 , have been involved in these undergraduate/graduate teams. We will discuss the development of leadership skills and work ethic that is inherent in these teams.

In the Fall semester of 2005, student 5 transferred to our university in her senior year. She immediately demonstrated a strong mathematical background. She also indicated an interest in graduate studies. Because of her math aptitude, we thought it appropriate to find a simulation project for her. With our encouragement, she decided to work on the development of image processing techniques for facial recognition. This effort resulted in a presentation at the National Conference for Undergraduate Research [6].

In the Fall semester of 2006, student 6 transferred to our university in his senior year and like student 5 immediately demonstrated a strong mathematical aptitude. He also expressed an interest in graduate studies. We thought it appropriate to team these students together. Student 5, who was now a graduate student in the Master of Science in Technology helped student 6 begin work on computer interpretation of Ammerican Sign Language. Very soon it became apparent that student 6 was very independent, and preferred to work alone. Therefore, we suggested that student 5 join another team. 
In the Fall semester of 2005, an ECET senior (student 7 in Table 1) who indicated interest in graduate studies worked on a senior design project which involved the acoustic monitoring of a gasoline engine. This student designed interface hardware to amplify the output of an a piezoelectric acoustic sensor. Further, this student developed a LabView data collection system to collect the sensor data. He also developed a Matlab algorithm to generate and display the frequency characteristics of the acoustic data.

In the Fall semester of 2006, student 7 joined our Master of Science in Technology program. Since student 7 had demonstrated a strong interest and ability in automated testing and hardware interface development, we decided to get him involved with the development of testing hardware and software to monitor and analyze data from a 3-dimensional accelerometer. This project is focused on the monitoring of human hand tremers but holds prospect for many applications involving motion detection and analysis. In this same semester, we teamed student 7 with a senior ECET student (student 8). Student 8 was similar to student 7 in that he also demonstrated a strong desire to work in hardware design. Student 7 , now a graduate student, soon trained student 8 , the senior, in how to implement data acquisition hardware and software. In the 2006 - 2007 academic year, student 8 built data acquisition hardware and designed data acquision software to collect motion data simultaneously from five 3D accelerometers. This capability to collect data from multiple accelerometers will be useful to the project team when termer data is analyzed in real-time at several points on the hand and forearm. We anticipate that this project will continue in the 2007 - 2008 academic year, in which student 8 will play a key role as a graduate student.

During this same semester, student 5, the graduate student who had worked in facial recognition as a senior, joined the graduate/undergraduate team working on motion detection and analysis. Because of her strong math abilities, we have her working on the implementation of mathematical techniques for the analysis and characterization of sensor data. The processes that she is focusing on are an empirical mode decomposition method for the detection of hand tremers and an autoregression (AR) model for adaptive signal processing of the hand tremer data. Since the AR model is an adaptive linear predictor, it is anticipated that it will be able to adaptively adjust to different patients. Eventually it is envisioned that these techniques could be implemented on an inexpensive portable digital signal processor-based device that would provide the signals necessary for real-time electromechanical suppression of hand tremers.

When we develop plans for a new project, we have found it beneficial to the student to get a senior working on the project during one academic year and then in the second year, when the 
student becomes a graduate student, we will team him/her with a senior working on the same project or a related project. This provides continuity to the student research and develops in the participants leadership skills associated with the management of a research project. We have also found that this teaming in some cases nutures a student's work ethic. A case in point is student 3. As a sophomore and junior, he was an under achiever. He was negligent on his assignments and performed only at an average level. In his senior year he blossomed as a student. He took intruction from student 1 (a grad student) very well and worked diligently to complete the UWB project. As a graduate student in the 2006 - 2007 academic year, he demonstrated a very impressive work ethic. While the cause and effect of such events are never be validated, it is possible that the undergraduate/graduate teaming efforts have played a role in the development of this student.

In the Fall semester of 2006, the ECET and EE faculty became involved with a project to investigate the RF characteristics of photonic structures. We decided that student researchers could help develop the test setup. So we teamed student 3, a graduate student, with student 4, a senior. Together they worked on using the UWB system as a source of RF energy in which to test the photonic structure. It is anticipated that this project will continue in the $2007-2008$ academic year.

\section{Conclusions}

We have introduced a method of creating small teams of undergraduate and graduate students. One of the benefits of this method is that it helps develop leadership skills and a strong work ethic in the student researchers. Another benefit is that it helps grow and strengthen a graduate program. Seniors become interested in graduate work because of the availabliilty of graduate/undergraduate teams. This interest creates a larger pool of graduate school applicants. Students who are teamed in their senior year with a graduate student are able to quickly adapt to working on a graduate research project when they become graduate students. Another benefit of this teaming method is that it improves the quality of work produced by a research project. This is accomplished because less time is devoted to the training of students for graduate work after they have been admitted to graduate school and a stronger emphasis is placed on individual responsibility. 


\section{References}

1. Zhang J. Z., Burbank K. and Adams R., A Systems Approach to Teaching "Introduction to Electronic Communications" for ECET Students, Proceedings of the 2004 American Society for Engineering Education Annual Conference \& Exposition, ASEE, June, 2004.

2. Zhang J. Z., Burbank K., and Adams R., A Modular Approach to Teaching "Wireless Communications and Systems" for ECET Students, Proceedings of the 2005 American Society for Engineering Education Annual Conference \& Exposition, ASEE, June, 2005.

3. Zhang, J. Z., Adams R., and Burbank, K., Theory, Practice, and Systems - A New Approach to Teaching Electronic Communications with Matlab ${ }^{\circledR}$. International Journal of Engineering Education. Vol. 21, No. 3, pp. 612-617, 2005.

4. Zhang, J. Z., Adams R., and Burbank, K., The Design of RF Labs using Mini-Circuits Modules to Improve the Quality of Teaching in a Course on Wireless Communications and Systems. World Transactions on Engineering and Technology Education. Vol. 4, No. 1, pp. 39-42, 2005.

5. Bengtson, F. and Heggen, S., A Data Communication System Using Ultra Wideband (UWB) Technology, Proceedings of the 2005 National Conference on Undergraduate Research (NCUR), Washington and Lee University, Virginia Military Institute, Lexington, Virginia, April 21-23, 2005.

6. Martin, X., User-Intent Based Electronic Information Retrieval (IR) Interface Using Image Processing Techniques, Proceedings of the 2006 National Conference on Undergraduate Research (NCUR), University of North Carolina at Asheville, Asheville, Virginia, April 6-8, 2006. 